\title{
Differential Changes in the Steady State Levels of Thylakoid Membrane Proteins during Senescence in Cucumis sativus Cotyledons
}

\author{
Jogadhenu S. S. Prakash ${ }^{\mathrm{a}, \mathrm{b}, *}$, Masroor A. Baig ${ }^{\mathrm{b}}$ and Prasanna Mohanty ${ }^{\mathrm{a}}$ \\ a School of Life Sciences, Jawaharlal Nehru University, New Delhi, India - 110067. \\ E-mail: syamsunderp@yahoo.com \\ b Department of Biochemistry, Jamia Hamdard, New Delhi, India - 110062 \\ * Autor for correspondence and reprint requests \\ Z. Naturforsch. 56c, 585-592 (2001); received January 26/March 26, 2001 \\ Cucumis sativus, Senescence, Thylakoids
}

Chloroplast structure and function is known to alter during foliar senescence. Besides, the alterations in the structural organisation of thylakoid membranes changes in the steady state levels of thylakoid membrane proteins occur due to leaf ageing. We monitored temporal changes in some of the specific proteins of thylakoid membrane protein complexes by western blotting in the Cucumis sativus cotyledons as a function of the cotyledon age. We observed that the levels of D1 and D2 proteins of photosystem II started declining at the early stages of senescence of Cucumis cotyledons and continued to decline with the progress of cotyledon age. Similarly the level of Cyt $f$ of Cyt $b_{6} / f$ complex declined rapidly with progress of senescence in these cotyledons. The reaction centre proteins of photosystem I were relatively found to be more stable than that of photosystem II reaction centre proteins reflecting possibly the disorganisation of photosystem II prior to photosystem I. The $33 \mathrm{kDa}$ extrinsic protein (MSP) of oxygen evolving complex, the LHCII apoprotein and the $\beta$-subunit of ATPsynthase showed the declined levels with the progress of cotyledon age. However, the extents of loss of these proteins were not as high as the reaction centre proteins of photosystem II and the Cyt $f$. These results provide that during senescence, proteins of thylakoid membranes degrade in a specific temporal sequence and thereby affect the temporal photochemical functions in Cucumis sativus cotyledons.

\section{Introduction}

Senescence is a physiologically programmed final phase of leaf developmental cycle. It induces the co-ordinated degradation of macromolecules mostly soluble and membrane proteins, which results in the remobilization of nutrients from old leaves to newly forming plant parts (Buchanan-

\begin{abstract}
Abbreviations: Chl, chlorophyll; CP47, chlorophyll binding protein of PSII; Cyt, cytochrome; LHCII, light harvesting chlorophyll protein II; MSP, manganese stabilising protein; PSII and PSI, Photosystem II and Photosystem I; PQH2, plastohydroquinone; SDS-PAGE, sodium dodecyl sulfate-polyacrylamide gel electrophoresis; DCBQ, 2,6-dichlorobenzoquinone; DCPIP 2,6-dichlorophenol indophenol; MV, methylviologen.
\end{abstract}

Present address: J. S. S. Prakash

West wing, Ground floor (W-112)

Center for Cellular and Molecular Biology (CCMB)

Uppal Road, Hyderabad - 500007

Andhra Pradesh, India.

Fax: 091-40-7171195. E-mail: syampra@ccmb.ap.nic.in

Syamsunderp@yahoo.com
Wollaston, 1997). The foliar senescence is usually associated with loss of pigments notably the chlorophylls, although loss of pigments is not the only criterion of ageing (Thomas, 1982). However, in many cases the loss of chlorophylls is a good indicator of senescence in leaves and cotyledons. Besides the loss in pigment contents, senescence also induces the decline of photosystem II, photosystem I and whole chain electron transport rates as well as photophosphorylation (Biswal and Mohanty, 1976; Sabat et al., 1989; Mc Rae et al., 1985; Holloway et al., 1983; Camp et al., 1982). The decline in the electron transport activities during foliar senescence is likely to be associated with the changes in the steady state levels of thylakoid membrane proteins and the consequent destabilisation of thylakoid membrane protein complexes as well as the chloroplast organisation (Grover, 1993; Biswal, 1997). The ageing induced destabilisation of thylakoid complexes has been assumed to occur in an ordered sequence (Grover and Mohanty, 1993). During senescence of Phaseolus leaves it has been shown that the rate of synthesis 
and degradation did not change during the period of senescence, where as the synthesis of many other thylakoid proteins such as Cyt $b_{6}$, Cyt $f, \alpha$, $\beta$ subunits of ATPase, apoprotein of LHCII were suppressed. These changes in synthesis of these proteins resulted in decrease of the steady state levels of Cyt $f$ and Cyt $b_{6}$ (Roberts et al., 1987). From these results the authors concluded that the senescence-induced alteration in the translation of membrane proteins controlled the levels of the thylakoid proteins, and also they suggested that the intersystem electron transport to become ratelimiting during senescence. Further, the content of Cyt $f$ of $C y t b_{6 / f}$ complex, which mediates electron transfer from PSII to PSI, has been shown to decrease in many senescing systems (Holloway et al., 1983; Hidema et al., 1991). Harnischfeger (1973) monitored the Chl / Cyt $f$ ratio in senescing Cucurbita leaves and suggested rapid degradation of Cyt $f$ during leaf senescence. A preferential loss of Chl $b$ and quantitative loss of the apoprotein of LHCII have been reported by Nock et al., (1992) and Mae et al., (1993). However, earlier report by Jenkins et al., (1981) indicated that, the antenna size associated with photosystem II reaction centre remained stable during senescence in Phaseolus vulgaris leaves. It is well known that the PSII activity gets reduced at the early stage of leaf senescence. Thus there have been reports on the loss of $32 \mathrm{kDa} \mathrm{D} 1$ protein and oxygenevolving complex (OEC) of PSII. Biswal et al. (1994) suggested a quantitative loss of the 32$\mathrm{kDa} \mathrm{Q}_{\mathrm{B}}$ binding protein, D1 in Festuca pratensis. In barley, decline in the oxygen evolution rates and a parallel loss of extrinsic proteins of PSII was reported by Choudhury and Imaseki, (1990). Unlike photosystem II activity the photosystem I photochemical functions were reported to be less affected during leaf senescence. However, the PSI complex was shown to degrade faster than that of PSII complex in soybean cotyledons (Bricker and Newman, 1982). The alterations in the ATPsynthase complex and photophosphorylation during leaf ageing has been reported in wheat and bean leaves (Camp et al., 1982; Roberts et al., 1987). These studies provide information of a possible time-dependent loss of thylakoid protein complexes, even though the exact sequence of losses appear to vary depending upon plant species and growth conditions.
The Cucumis cotyledons are an useful model system for investigation on senescence as the cotyledons are programmed for senescence during seedling establishment and also extensively used in physiological studies. No detailed analyses on the levels of changes in thylakoid proteins in cotyledons have been made. In this study, we present results of changes in the steady-state levels of selected proteins belonging to PSII, PSI and Cyt $b_{6 / f}$ complexes of Cucumis thylakoid membranes to evaluate the degree and sequence of losses during cotyledon senescence. Our results demonstrate that the loss of these membrane proteins occurs sequentially in defined order.

\section{Materials and Methods}

Seeds of Cucumis sativus cv. Poinsette were surface-sterilised with $0.1 \%$ mercuric chloride for 3 to $5 \mathrm{~min}$ and then rinsed thoroughly with distilled water. The cleaned seeds were placed in glass bottles $(24 \times 10 \mathrm{~cm})$ on a $2-\mathrm{cm}$ thick cotton bed moistened with $\sim 250 \mathrm{~cm}^{3}$ of autoclaved mineral nutrient medium as described earlier (Prakash et al., 1998) containing essential macronutrients and micronutrients. Seedlings were raised in a growth chamber maintained at $25 \pm 2{ }^{\circ} \mathrm{C}$ under continuous white fluorescent light of $35-40 \mu \mathrm{mol} \mathrm{m}^{-2} \mathrm{~s}^{-1}$ and relative humidity of $85-90 \%$. Plants were grown for 3-4 weeks and cotyledons were harvested at 6, 15, 20, 27 days after germination.

\section{Estimation of chlorophyll and protein contents}

Chlorophylls (Chl) were extracted in chilled $100 \%$ dimethyl formamide in dark, and their amounts were estimated according to Porra et al., (1989) and expressed as $\mathrm{mg} \mathrm{g}^{-1}$ dry weight. Leaf proteins were precipitated with $10 \%$ trichloroacetic acid, dissolved in $1 \mathrm{~N} \mathrm{NaOH}$ and the total amount of proteins was estimated according to Lowry et al.(1951) using bovine serum albumin as standard. Total cotyledon protein contents were expressed as $\mathrm{mg} \mathrm{g}^{-1}$ dry weight.

\section{Measurement of photochemical activities}

Thylakoid membranes were isolated by the procedure similar to that of Nakatani and Barber (1977) as described in Vani et al. (1996). Electron transport rates of isolated thylakoids were mea- 
sured polarographically in terms of oxygen consumption or evolution at $25^{\circ} \mathrm{C}$ and $\sim 700 \mu \mathrm{mol}$ (photon) $\mathrm{m}^{-2} \mathrm{~s}^{-1}$, using Clark type oxygen electrode (Hansatech, U. K.) as described earlier (Prakash et al., 1998). The electron transport rates were expressed as $\mu$ mol $\mathrm{O}_{2}$ (evolved / consumed) $\mathrm{mg}^{-1}$ Chl. $\mathrm{h}^{-1}$.

\section{Urea-SDS PAGE and Western blot analysis}

Samples for urea-SDS denaturing polyacrylamide electrophoresis were prepared by mixing thylakoid membranes in sample buffer containing $6 \mathrm{~m}$ urea, $2 \% \mathrm{w} / \mathrm{v}$ sodium dodecyl sulfate, $2.5 \%$ w/v $\beta$-mercaptoethanol, $62.5 \mathrm{~mm}$ Tris [2-amino-2(hydroxymethyl) propane-1,3-diol]-HCl ( $\mathrm{pH} 6.8$ ) and $10 \% \mathrm{w} / \mathrm{v}$ glycerol. The mixture was incubated for 20-30 min at room temperature with intermittent shaking. The sample was then centrifuged at high speed for $2 \mathrm{~min}$. prior to loading. Thylakoids equivalent to $15 \mu \mathrm{g}$ of protein was loaded per lane. Electrophoresis was carried out using Bio-Rad's Mini-Protein II gel electrophoresis system. Western blot analyses of thylakoid membrane proteins were carried out in Bio-Rad's Mini transblot apparatus according to Towbin et al. (1979). After the electrophoresis the proteins on the gels were transferred to nitro-cellulose membrane and processed for immunoblotting with respective antibody (s). Primary antibodies obtained as gifts from various sources were diluted to specified concentration in Tris-buffer saline containing $0.5 \%$ gelatine. These antibodies only reacted with the specific target proteins and did not give any crossreactions, except for $\mathrm{CP} 47$, where a few minor additional bands were observed. However, this crossreaction did not interfere with the results as we evaluated the area and intensity of the protein band in the range of $46-47 \mathrm{kDa}$ region representing the molecular mass of CP47 for quantification. The secondary antibody (Alkaline phosphatase) was purchased from Sigma and diluted 1:32,000 for use. All the Western blot analyses were performed at least three times and the blots presented represent the typical ones. Percentage changes of the protein in senescing samples with respect to the 6day control sample were calculated from the area and intensity of the protein band on the blot using Image analysis and gel documentation solutions, AN Gel Biosystems, Sherman Oaks CA-91413, equipped with Electronic Dual LightTM transilluminator. The Western blots were transilluminated and the images were transferred to computer. The software program (RELP advanced software, AAB program) provided with the instrument automatically calculates the area and intensity of each protein band selected. The area and intensity of control protein band on each blot was taken as $100 \%$ and the protein bands of senescing samples were calculated accordingly.

\section{Results and Discussion}

Even though loss of pigment is not a specific indicator of ageing, the loss of photosynthetic pigments is one of the visible changes that occur during leaf senescence. We thus measured the total $\mathrm{Chl}$, besides total protein contents in the cotyledons at various periods of growth of Cucumis sativus. The total chlorophyll as well as the total protein contents gradually increased from the day of seed germination and found to be maximum in the 6-day grown cotyledons and thereafter a gradual decline was observed. We also monitored the chloroplast photochemical activities during the same intervals. Fig. 1, shows the changes in the chlorophyll, protein, PSII-catalysed electron transport activity and PSI activity with the progress of cotyledon age. Approximately $67 \%$ and $57 \%$ of losses in total $\mathrm{Chl}$ and cotyledon protein were observed in 27-day old cotyledons with respect to 6-day ones taken as control because of maximal value of measured parameters. In this study, we have considered the 6-day Cucumis cotyledons as fully developed state as at this time the cotyledons were fully developed and maximally active and 15, 20, 27-day-old Cucumis cotyledons as senescing situations. Unlike in rice or wheat seedlings (KuraHotta et al., 1987; Sabat et al.,1989), marginal changes in the $\mathrm{Chl} a / b$ ratio was observed during the ageing in Cucumis cotyledons indicating possibly a parallel loss of the Chl $a$ of core antenna (CP 47 and $\mathrm{CP} 43$ ) and the peripheral antenna (LHCII) of PSII complex. Kura-Hotta et al. (1987) proposed from their studies on senescence with rice seedlings that a preferential loss of $\mathrm{Chl} a$ over $\mathrm{Chl} b$, was linked to the initial degradation of $\mathrm{Chl}$ $a$ containing core antenna of PSII at the advancement of senescence. In Cucumis cotyledons this does not seem to be the case. 


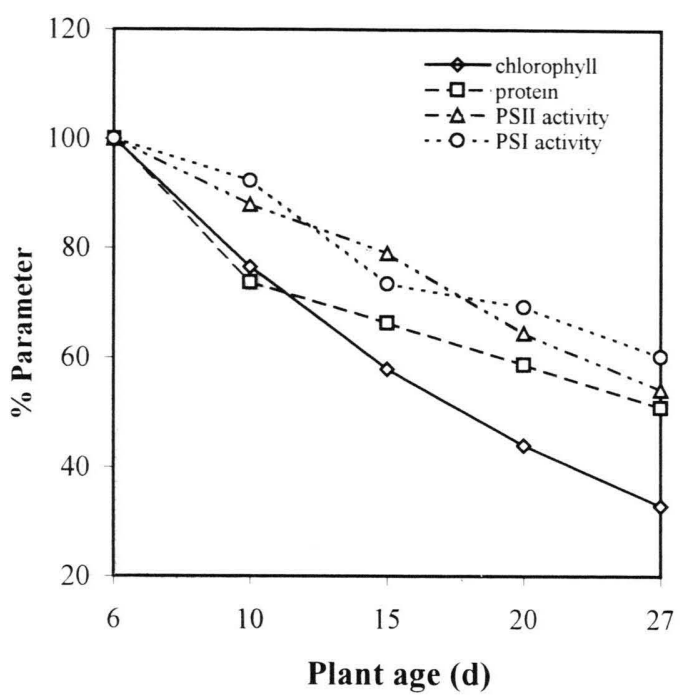

Fig. 1. Age dependent changes in total chlorophyll, total protein content, and PSII and PSI activities in Cucumis sativus cotyledons. Total Chlorophyll and total cotyledon protein contents were estimated according to the procedures of Porra et al. (1989) and Lowry et al. (1951). The PSII $\left(\mathrm{H}_{2} \mathrm{O}\right.$ to DCBQ) and PSI activity $\left(\mathrm{DCPIPH}_{2}\right.$ to $\mathrm{MV}$ ) were measured in the isolated thylakoid membranes as described in materials and methods. Chlorophyll and protein contents of cotyledons were expressed as $\mathrm{mg} \mathrm{g}^{-1}$ dry weight. The PSII activities were expressed as $\mu$ mole $\mathrm{O}_{2}$ evolved $\mathrm{mg}^{-1} \mathrm{Chl} . \mathrm{h}^{-1}$. The PSI activities were expressed as $\mu$ mol $\mathrm{O}_{2}$ consumed $\mathrm{mg}^{-1} \mathrm{Chl} \mathrm{h}^{-1}$. Chlorophyll, protein contents and electron transport rates of control 6-day samples were taken as $100 \%$ and the relative changes in these parameters of senescing samples were calculated accordingly.

The thylakoid membranes of 6 day grown cotyledons exhibited maximal PSII-catalyzed oxygen evolution with DCBQ as an electron acceptor near $\mathrm{Q}_{\mathrm{A}}$, the stable primary electron acceptor of PSII (Satoh et al., 1992). The quinone-supported Hill activity of PSII steadily declined with the progress of cotyledon age (Fig. 1). The thylakoids isolated from 27 -day cotyledons showed $\sim 46 \%$ loss of PSII activity when compared to 6-day samples. However, the PSI activity monitored as DCPIPH ${ }_{2}$-supported MV reduction and oxidation by molecular oxygen also exhibited a $39 \%$ loss of activity in 27 day (Fig. 1). In a variety of test systems, a greater extent of loss in PSII activity over PSI activity has been reported earlier (Jenkins and Woolhouse, 1981; Choudhury and Imaseki, 1990; Sabat et al., 1989). However, these results do not specifically suggest a greater susceptibility of PSI to ageing than PSII possibly because of the differential sen- sitivities of the two assays. We therefore monitored the time dependent changes in the relative levels of specific proteins from four major thylakoid protein complexes, namely PSII complex, Cyt $b_{6} / f$ complex, PSI complex and ATPsynthase. Using specific antisera we monitored the steady state levels of selected proteins from these four complexes. The polypeptide profiles of the senescing thylakoid samples were similar to that of 6-day control thylakoid sample. However, the intensity of the many of the Coomassie-stained polypeptide bands showed significant decrease in senescing thylakoid samples relative to the 6-day thylakoid sample (data not shown).

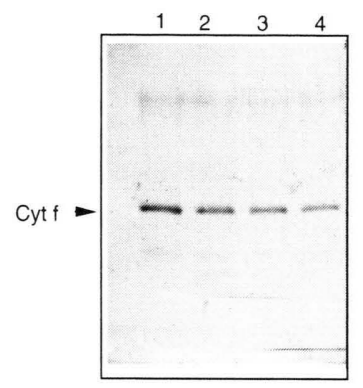

Fig. 2. Western blot of the Cyt $f$ of Cyt $b_{6 / f}$ complex in 6(non-senescing) 15, 20 and 27-day senescing Cucumis cotyledon thylakoid samples respectively. Polypeptides of the thylakoid samples, were resolved on $12 \%$ acrylamide gel containing $6 \mathrm{~m}$ urea in BioRad's Mini-gel electrophoresis system. Samples were loaded on equal protein basis $(15 \mu \mathrm{g}$ of protein per lane). Lanes $1-4$ in each blot represent $6,15,20$ and 27 -day samples respectively.

Fig. 2 shows the Western blot of Cyt $f$ of Cyt $b_{6 /}$ $f$ complex in the thylakoids isolated from $6,15,20$ and 27-day cucumber cotyledons. The Cyt $f$ which mediates the electron transfer from $\mathrm{PQH}_{2}$ to $\mathrm{PC}$, showed about $35 \%, 50 \%$ and $59 \%$ decline in its amount in 15, 20, 27 day samples respectively as compared to the 6-day control (Fig. 2). Since, Cyt $f$ level decreased significantly in the early stages of senescence, and it continued to decline with the progress of senescence. This protein seemed to be very labile during ageing. This indicates that, the intersystem electron transfer components gets affected early due to senescence. Similarly functional analysis involving linear electron flow and PSII electron flow also reflects that the extent of loss in the linear electron flow was more than PSII (Harnischfeger, 1973; Jenkins and Woolhouse, 1981; Holloway et al., 1983; Roberts et al., 1987; 
Hidema et al., 1991). This may be ascribed to susceptibility of Cyt $f$ to senescence. Recently, we showed a possible alteration in the electron transfer from $\mathrm{PQH}_{2}$ to Cyt $b_{6 / f}$ complex during Cucumis sativus cotyledon senescence (Prakash et al., 1998). Thus from both functional studies as well as the measurement of steady state levels, it is clear that Cyt $f$ of Cucumis cotyledon thylakoids is an early site of damage during ageing.

Any structural changes or declined levels of PSII reaction centre proteins will have adverse effect on the photochemical reaction catalysed by PSII. Western blots of the polypeptides D1 and D2 for 6, 15, 20 and 27-day thylakoid samples are shown in Fig. 3A and B. In 15, 20 and 27-day, D1 protein levels decreased by $25 \%, 47 \%$ and $56 \%$, respectively when compared to the 6 day control sample (Fig. 3A). Similarly, $14 \%, 40 \%$ and $43 \%$ losses in the D2 protein were observed (Fig. 3B). In the early stages of senescence (i.e., in 15-day cotyledon samples) the loss of D1 protein was higher than that of D2 protein. The steady-state levels of these proteins continued to decline with the progress of senescence. These results are consistent with the earlier report where the D1 protein has been shown to decline in senescing Festuca pratensis (Biswal et al., 1994). The D1 protein is known to have a higher turnover than D2 (Mattoo and Edelman, 1987) and we assume that the rate of synthesis of D1 and D2 proteins do not
(A)

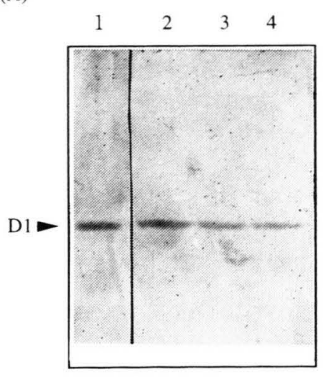

(B)

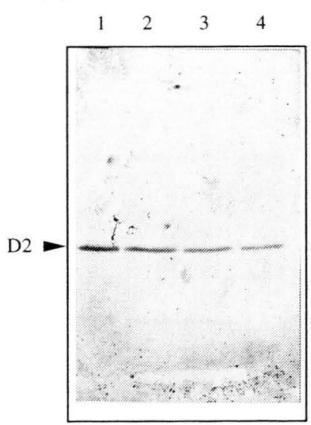

Fig. 3A and B. Western blots of the reaction centre proteins D1 and D2 of photosystem II in 6(non-senescing) 15, 20 and 27-day senescing Cucumis cotyledonary leaf thylakoid samples respectively. Polypeptides of the thylakoid samples were resolved on $12 \%$ acrylamide gel containing $6 \mathrm{~m}$ urea in BioRad's Mini-gel electrophoresis system. Samples were loaded on equal protein basis (15 $\mu \mathrm{g}$ of protein per lane). Lanes $1-4$ in each blot represent $6,15,20$ and 27 day samples respectively. change during the period of senescence in $\mathrm{Cu}$ cumis as in Phaseolus(Roberts et al., 1987). So, the extent of loss of D1 protein must be due to its rapid degradation during senescence. The steadystate level of this protein almost parallels with the Cyt $f$ during senescence.

Western blots of chlorophyll binding proteins of PSII, the CP47, LHCII and the 33-kDa extrinsic protein (MSP) of oxygen evolving complex(OEC) are given in Fig. 4A, B and $\mathrm{C}$ respectively. We observed about $27 \%$ and $36 \%$ losses in LHCII protein in 20 and 27-day samples as compared to 6day control. No significant change in the LHCII of 15-day sample was observed with reference to control 6-day thylakoid sample. Similarly, about $25 \%$ and $32 \%$ decline in the CP47 polypeptides
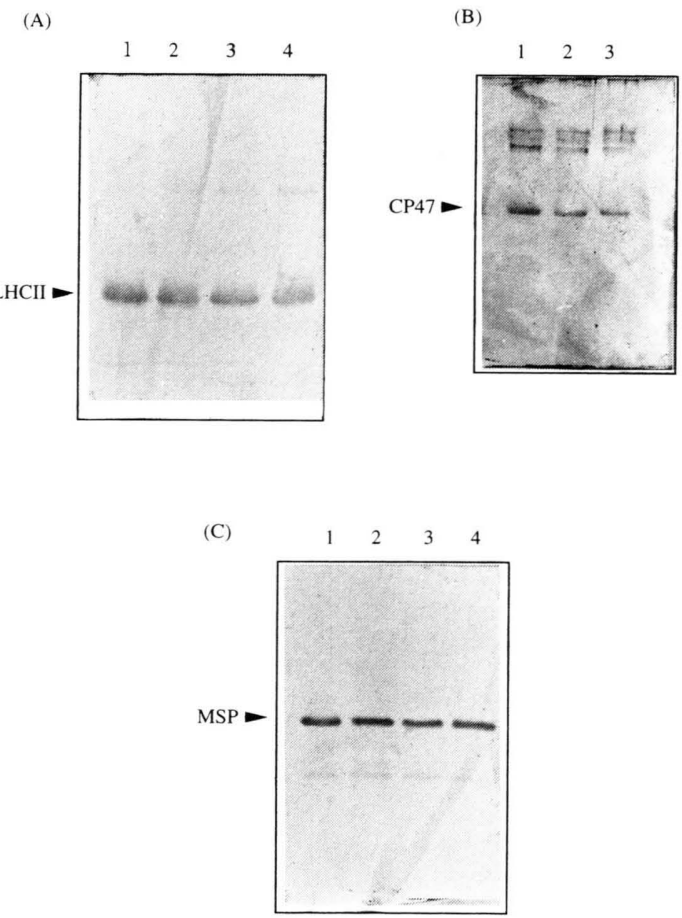

Fig. 4A, B and C. Western blots of chlorophyll binding proteins LHCII, CP47 of photosystem II and $33 \mathrm{kDa}$ extrinsic protein (MSP) of oxygen evolving complex respectively. Polypeptides of the thylakoid samples were resolved on $12 \%$ acrylamide gel containing $6 \mathrm{M}$ urea in BioRad's Mini-gel electrophoresis system. Samples were loaded on equal protein basis ( $15 \mu \mathrm{g}$ of protein per lane). In Fig. 4A and C Lanes 1-4 represent the LHCII and MSP levels in the thylakoids isolated from $6,15,20$, and 27-day Cucumis cotyledons. In Fig 4B, lanes 1-3 represent the CP47 of the thylakoids isolated from 6, 20 and 27- day cotyledons. 
were observed. This may indicate a parallel loss in the core (CP47) and peripheral antenna (LHCII proteins) of PSII with progress of senescence. As stated earlier Kura-Hotta et al. (1987) reported that, the damage of core antenna which contains only $\mathrm{Chl} a$, occur prior to the LHCII (the peripheral antenna to which most of the $\mathrm{Chl} b$ is associated) suggesting a decrease in the $\mathrm{Chl} a / b$ ratio in rice seedlings, where a gradient development of chloroplasts occur in the same leaf, unlike the $\mathrm{Cu}$ cumis. Thus in Cucumis cotyledons both core and peripheral PSII antenna seemed to get affected equally. From Fig. 4C, we note that no change in the $33 \mathrm{kDa}$ extrinsic protein in 15-day sample. However, in later stages of senescence (in 20 and 27 -day thylakoid samples) about $20 \%$ and $33 \%$ losses were observed. It has been proposed that the disassembly of PSII proceeds in the sequence, beginning with the disorganisation of its oxygenevolving system, followed by damage of the RC complex and finally loss in the LHCs (Biswal, 1997). However, our results in Cucumis sativus cotyledons suggested that the reaction centre of PSII damage possibly occurs earlier than MSP and the LHCII. It is possible that the pattern of loss in the complexes varies in different plants and depends on growth conditions.

Fig. 5A shows the Western blots probed with the anti PsaA/PsaB (PSI reaction centre) in 6 day and senescing thylakoid samples. About 12,14 and $20 \%$ losses in the PSI reaction centre were observed in 15, 20 and 27-day thylakoid samples respectively as compared to 6-day control. Thus

(A)

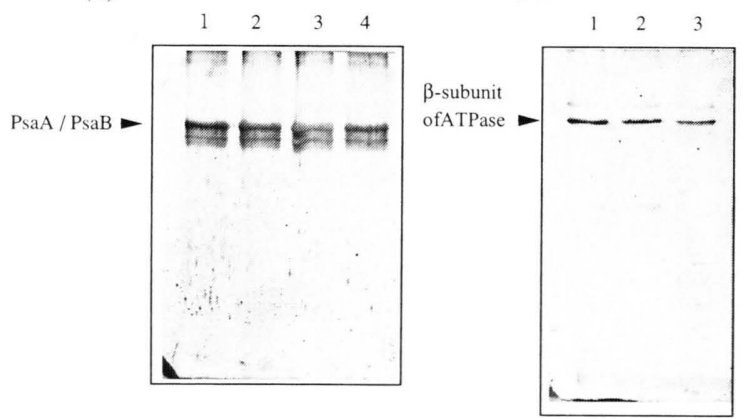

Fig. 5A and B. Western blots of the reaction centre protein of photosystem I (A), and the $\beta$-subunit of ATP synthase (B). Lanes 1-4 in (A) represent 6, 15, 20 and 27-day samples respectively. Lanes $1-3$ in (B) represent 6, 20 and 27-day samples.
PSI reaction centre protein was found quite stable when compared to the PSII reaction centre proteins during cotyledon senescence (Fig. 5A). Although the losses in uncoupled electron transport activity of both the photosystems were identical, our results suggest that the damage in the PSII in Cucumis cotyledons occurs prior to the PSI damage due to ageing. However, according to Bricker and Newman (1982), the PSI complex degrades faster than that of PSII complex in soybean cotyledons. At present, we can not explain this difference. Our results clearly show that PSII reaction centre proteins are strongly affected during senescence.

The reduction in photophosphorylation during leaf ageing has been reported in wheat and bean leaves (Camp et al., 1982; Roberts et al., 1987). We therefore measured the steady state level of $\beta$-subunit of ATPsynthase. Western blot of the $\beta$-subunit of ATPsynthase during progress of senescence is shown in Fig 5 B. Approximately $23 \%$ and $34 \%$ decline in the amount of this protein were observed in 20 and 27-day samples, respectively. The change in the levels of this protein paralleled with the losses of LHCII and MSP of PSII during senescence of Cucumis cotyledons.

We could evaluate the relative changes in the percentage of various proteins of the thylakoid protein complexes from 15, 20 and 27-day $\mathrm{Cu}$ cumis cotyledons with respect to 6 day ones. These changes are documented as bar diagrams (Fig. 6A, $\mathrm{B}$ and C). Fig. 6 also provides temporal sequence of losses in the various selected thylakoid membrane proteins except Cyt $b_{559}$, which showed no significant change in its steady state levels throughout senescence. The Cyt $f$, D1 and D2 proteins account for higher losses when compared to other membrane proteins analysed. PSI reaction centre protein was found to be more stable than that of PSII reaction centre proteins D1 and D2. There was no major loss in the steady state levels of MSP of OEC in the early stages of senescence. These were affected at late stages of senescence. The magnitude of comparative loss of these membrane proteins could be thus arranged in the following order during Cucumis sativus cotyledon senescence and this sequence may reflect a temporal sequence of changes as follows.

Cyt $f>$ D1 > D2 > LHCII > MSP > PSI RC 


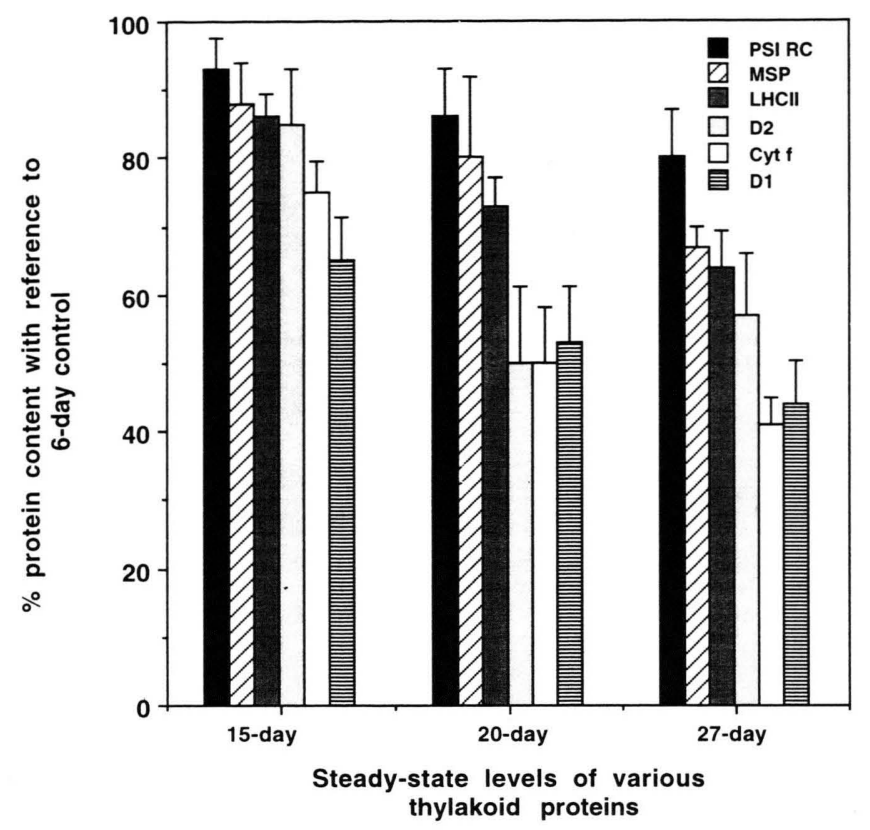

Fig. 6. Differential changes in the steady state levels of thylakoid membrane proteins analyzed by western blot method in $15^{\text {th }}, 20^{\text {th }}$, and $27^{\text {th }}$ day Cucumis sativus cotyledons. The intensity of the protein band in the Western blot for 6-day thylakoid samples was taken as $100 \%$ and, the percentage of changes in each protein in senescing samples were calculated. The values are mean ( \pm standard deviation) of three observations. The steady-state levels of Cyt $f$ of the Cyt $b_{6 / f}$ complex, and the D1 and D2 proteins of PSII, started declining in the early stages of the senescence and continued to decline with the progress of senescence. Photosystem I reaction centre proteins, MSP (33 kDa) are relatively quite stable in contrast to the Cyt $f$, D1 and D2 proteins.

However, We do not know whether these temporal changes were co-ordinated and regulated during the progress of senescence.

\section{Acknowledgements}

The work is supported by a grant from DAEBRNS (Project No 4/3/95-R\&D-II) to PM. Anti D1 synthetic peptide antibody for D1 and anti spinach D2 antibody were gifts from Dr. Ikeuchi. MSP (manganese stabilising protein) antiserum raised against spinach MSP in a rabbit was a gift from Dr. T.Kuwabara. Antibodies for PSI PsaA/ $P s a B$ and general LHCII antibodies were gifts from Dr. I. Enami and Dr. J. Meehl, respectively.
The CP47 antiserum was a gift of Dr. K. Satoh. The antibody raised against the ATP synthase was a generous gift from Dr. A.Watanabe. The antibody raised against the Cyt $f$ was a gift from Dr. Tuli. We thank Dr. A. Watanabe University of Tokyo, Japan; Dr. K. Satoh, Himeji Institute of Technology, Japan; Dr. M. Ikeuchi, University of Tokyo, Japan; Dr. T. Kuwabara, University of Tsukuba, Japan; Dr. J. Meehl, University of Colorado; Dr. R. K. Tuli, NBRI, Lucknow, India and Dr. I. Enami, Science University of Tokyo, Japan for the generous gifts of antibodies and valuable suggestions on their use. Sincere thanks to Dr. A. S. Bhagwat, Bhabha Atomic Research Centre, Mumbai, India for his valuable suggestions. 
Biswal U. C. and Mohanty P. (1976), Ageing induced changes in photosynthetic electron transport of detached barley leaves. Plant Cell Physiol. 17, 323-331.

Biswal B., Rogers L. J., Smith A. J. and Thomas H. (1994), Carotenoid composition and its relationship to chlorophyll and D1 protein during leaf development in a normally senescing cultivar and a stay-green mutant of Festuca pratensis. Phytochemistry 37, 12571262.

Biswal B. (1997), Chloroplast metabolism during leaf greening and degreening. In: Handbook of Photosynthesis (Pessarakli, M., ed.). Marcel Dekker, Inc., New York, pp 71-81.

Bricker T. M. and Newman D. W. (1982), Changes in the chlorophyll-proteins and electron transport activities of soybean (Glycine Max L. CV. Wayne) cotyledon chloroplasts during senescence. Photosynthetica 16, 239-244.

Buchanan-Wollaston V. (1997), The molecular biology of leaf senescence. J. Exp. Bot. 48, 181-199.

Camp P. J., Huber S. C., Burke J. J. and Moreland D. E. (1982), Biochemical changes that occur during senescence of wheat leaves. I. Basis for the reduction of photosynthesis. Plant Physiol. 70, 1641-1646.

Choudhury N. K. and Imaseki H. (1990), Loss of photochemical functions of thylakoid membranes and PSII complex during senescence of barley leaves. Photosynthetica 24, 436-445.

Grover A. (1993), How do senescing leaves lose photosynthetic activity? Curr. Science 64, 226-233.

Grover A. and Mohanty P. (1993), Leaf senescence-induced alterations in structure and function of higher plant chloroplasts. In: Photosynthesis, Photoreactions to Plant Productivity' (Abrol Y. P. Mohanty P and Govindjee eds.). Mohan Primlani for Oxford \& IBH publishing Co. Pvt.Ltd., New Delhi, pp. 225-255.

Harnischfeger G. (1973), Chloroplast degradation in ageing cotyledons of pumpkin. J. Exp. Bot. 24, $1236-1246$.

Holloway P. J., Maclean D. J. and Scott K. J. (1983), Rate-limiting steps of electron transport in chloroplasts during ontogeny and senescence of barley. Plant Physiol. 72, 795-801.

Hidema J., Makino A. Mae T. and Ojima K. (1991), Photosynthetic characteristics of rice leaves aged under different irradiance from full expansion through senescence. Plant Physiol. 97, 1287-1293.

Jenkins G. I., Baker N. R. and Woolhouse H. W. (1981), Changes in chlorophyll content and organisation during senescence of the primary leaves of Phaseolus vulgaris L. in relation to photosynthetic electron transport. J. Exp. Bot. 32, 1009-1020.

Jenkins G. I. and Woolhouse H. W. (1981), Photosynthetic electron transport during senescence of the primary leaves of Phaseolus vulgaris L. II. The activity of photosystems one and two, and a note on the site of reduction of ferricyanide. J. Exptl. Bot. 32, 989-997.

Kura-Hotta M., Satoh K. and Katoh S. (1987), Relationship between photosynthesis and chlorophyll content during leaf senescence of rice seedlings. Plant Cell Physiol. 28, $1321-1329$.
Lowry O. H., Rosebrough N. J., Farr A. L. and Randall R. J. (1951), Protein measurement with the Folin phenol reagent. J. Biol. Chem. 193, 265-275.

Mae T., Thomas H., Gay A. P., Makino A. and Hidema J. (1993), Leaf development in Lolium temulentum: Photosynthesis and photosynthetic proteins in leaves senescing under different irradiences. Plant Cell Physiol. 34(3), 391-399.

Mattoo A. K. and Edelman M. (1987), Intramembrane translocation and posttranslational palmitoylation of the chloroplast $32-\mathrm{kDa}$ herbicide-binding protein. Proc. Natl. Acad. Sci. USA, 84, 1497-1501.

McRae D. G., Chambers J. A. and Thompson J. E. (1985), Senescence-related changes in photosynthetic electron transport are not due to alterations in thylakoid fluidity. Biochim. Biophys. Acta 810, 200-208.

Nakatani H. Y. and Barber J. (1977), An improved method for isolating chloroplasts retaining their outer membranes. Biochim. Biophys. Acta 461, 510-512.

Nock L. P., Rogers L. J. and Thomas H. (1992), Metabolism of protein and chlorophyll in leaf tissue of Festuca pratensis during chloroplast assembly and senescence. Phytochemistry 31(5), $1465-1470$.

Porra R. J., Thompson W. A. and Kriedemann P. E. (1989), Determination of accurate extinction coefficients and simultaneous equations for assaying chlorophylls $a$ and $b$ extracted with four different solvents: Verification of the concentration of chlorophyll standards by atomic absorption spectroscopy. Biochim. Biophys. Acta 975, 384-394.

Prakash J. S. S., Baig M. A. and Mohanty P. (1998), Alterations in electron transport characteristics during senescence of Cucumis cotyledonary leaves, Analysis of the effects of inhibitors. Photosynthetica 35(3), 345-352

Roberts D. R., Thompson J. E., Dumbroff E. B., Gepstein S. and Mattoo A. K. (1987), Differential changes in the synthesis and steady-state levels of thylakoid proteins during bean leaf senescence. Plant Mol. Biol. 9, 343-353.

Sabat S. S., Grover A. and Mohanty P. (1989), Senescence induced alteration in the electron transport in wheat leaf chloroplasts. J. Photochem. Photobiol. B3, $175-183$.

Satoh K., Koike H., Ichimura T. and Katoh S. (1992), Binding affinities of benzoquinones to the $\mathrm{Q}_{\mathrm{B}}$ site of photosystem II in Synechococcus oxygen-evolving preparation. Biochim. Biophys. Acta 1102, 42-52.

Thomas H. (1982), Leaf senescence in a non-yellowing mutant of Festuca pratensis. I. Chloroplast membrane polypeptides. Planta 154, 212-218.

Towbin H., Staehelin T. and Gordon J. (1979), Electrophoretic transfer of proteins from polyacrylamide gels to nitrocellulose sheets: Procedure and some applications. Proc. Natl. Acad. Sci. USA 76, 4350-4354.

Vani B., Saradhi P. P. and Mohanty P. (1996), Effect of short-term heat treatment of rice seedlings on sensitivity of thylakoid membranes to photoinhibition. Biol. Plant. 38, 501-509. 